\title{
New concept on the origin of petroleum and natural gas deposits
}

\author{
J. Marvin Herndon ${ }^{1}$
}

Received: 2 November 2015/ Accepted: 15 July 2016/Published online: 23 July 2016

(c) The Author(s) 2016. This article is published with open access at Springerlink.com

\begin{abstract}
The scientific basis that underlies the geology of petroleum and natural gas deposit origination has for the past five decades been based upon plate tectonics theory. However, plate tectonics theory depends critically upon physically impossible mantle convection. I have disclosed a new indivisible geoscience paradigm, called whole-Earth decompression dynamics, that begins with and is the consequence of our planet's early formation as a Jupiter-like gas giant and which permits deduction of: (1) earth's internal composition and highly reduced oxidation state; (2) core formation without whole-planet melting; (3) powerful new internal energy sources, protoplanetary energy of compression and 'georeactor' nuclear fission energy; (4) mechanism for heat emplacement at the base of the crust; (5) georeactor geomagnetic field generation; (6) decompression-driven geodynamics that accounts for the myriad of observations attributed to plate tectonics without requiring physically impossible mantle convection; and (7) a mechanism for fold-mountain formation that does not necessarily require plate collision. Here, I describe from that new framework the scientific basis that underlies a new concept for the geological origin of petroleum and natural gas deposits.
\end{abstract}

Keywords Abiotic petroleum - Rifting $\cdot$ Mantle convection · Petroleum exploration · Whole-Earth decompression dynamics · Deccan Traps · Siberian Traps . Plume $\cdot$ Sedimentary basin

\footnotetext{
J. Marvin Herndon mherndon@san.rr.com

1 Transdyne Corporation, 11044 Red Rock Drive, San Diego, CA 92131, USA
}

\section{Introduction}

Surface observations of oil and gas seeps, the traditional technique for exploration of subsurface petroleum and natural gas deposits, is still currently in use. Surface observations, however, are now augmented by a host of highly sophisticated technologies to detect and determine the extent of such deposits, including surface geochemical investigations and subsurface geophysical investigations, such as seismic, electrical conductivity, and gravity surveys. With vast financial resources being brought to bear, and with many highly trained, competent specialists employed in those investigations, how, one might ask, can the likelihood of making new discoveries be enhanced?

Long experience has taught me this about the progress of science: Communities of scientists typically work within a framework of common understanding, rarely questioning the scientific basis of that understanding. Then along comes a scientist with a fundamentally new insight that calls into question the framework of that common understanding and sheds light on a new more-correct basis of understanding; a new paradigm which admits a host of new discoveries (Kuhn 1962). For example, in the classical, pre-quantum physics paradigm, an ideal black body at thermal equilibrium was calculated to emit radiation with essentially infinite power in the shorter wavelengths, the so-called ultraviolet catastrophe, a physical impossibility. A scientist of the early twentieth century (in late twentieth century language) might likely have asked, "What's wrong with this picture?" The answer in this historically significant example is that light is not continuous; classical physics ceases to hold in the domain now better explained by quantum physics. So, one might ask, what does this have to do with exploration for petroleum and natural gas deposits? The quick answer is to ask the following question: "What's

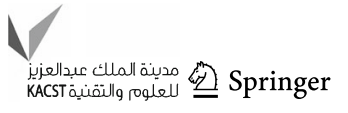


wrong with the scientific basis that underlies the geology of petroleum and natural gas deposit origination?" The answer to that question is the subject of the present article, which is based upon and amplifies my Current Science article, entitled "Impact of Recent Discoveries on Petroleum and Natural Gas Exploration: Emphasis on India" (Herndon 2010).

In order to present and justify a new concept on the origin of petroleum and natural gas, it is desirable to show not only what is wrong with the present, popular view, but to show what went wrong from a historical perspective. I briefly review ideas of continental displacement since the sixteenth century cartographic observations that suggest the continents were once joined and then separated. I then focus on the mechanism of continent locomotion, mantle convection, first suggested some 85 years ago, that is a pillar of plate tectonics theory. Then I describe why mantle convection is physically impossible and tender a new geodynamic theory that stems from a different understanding of the nature of Earth's early formation as a Jupiter-like gas giant. Decompression from Earth's early protoplanetary compression explains geological and geodynamic observations formally attributed to plate tectonics without necessitating mantle convection. This new geodynamic theory provides a basis for my proposal of a new concept on the origin of petroleum and natural gas.

\section{What's wrong with this picture?}

In the natural sciences, observations produce ideas, which may ultimately lead to understanding. The journey from observation to understanding may be long and arduous, often interrupted by discoveries not yet made or diverted by misunderstandings. Ultimately, though, when understanding is achieved, the pieces of the puzzle fit together, causal and logical relationships become evident, and often point the way toward new, yet unanticipated discoveries.

The Earth has existed for about $4 \frac{1}{2}$ billion years, but the mapmakers' reasonably complete, reliable representations of its surface were only available after the four voyages of Christopher Columbus between the years 1492 and 1504. In the years surrounding 1570, the Flemish mapmaker, Abraham Ortelius, produced several maps of the world which for the first time began to resemble our modern satellite-imaged, global view of Earth (Brown 1979).

From those maps, Ortelius observed the similarities in the shapes of the eastern coastlines of the Americas and the western coastlines of Europe and Africa. That observation led to his 1596 idea that the Americas were torn away from Europe and Africa by earthquakes and floods. The central idea is that the continents were previously attached and then were separated. This idea appears again and again, albeit with different explanations for the underlying cause. For example, the French prior, François Placet in 1668, the German theology professor, Theodor Christoph Lilienthal in 1756, and the French mapmaker, Antonio Snider-Pellegrini in 1858, each noted the apparent fit of the continent coastlines, as had Ortelius, and each proposed that separation was caused by biblical events. Snider-Pellegrini (1858) published a pair of globe-images showing a closefitting concentration of continents before and after their separation, which he attributed to a volcanic explosion on the sixth day of Creation. Snider-Pellegrini, however, went further by noting the similarity of fossil plants in coal beds of North America and Europe and by publishing a 'supercontinent reconstruction'. From the coal-bed fossils, he deduced the joined continents existing as recently as about 300 million years ago.

Remarkably, Snider-Pellegrini's image is similar to the "Urkontinent"-later "Pangaea"_of Alfred Wegener's continental drift theory, published first as a journal article (Wegener 1912), then in 1920 in a book in German, Die Entstehung der Kontinente und Ozeane, and in English (Wegener 1929), The Origin of Continents and Oceans.

During the first half of the twentieth century, members of geological establishment tended to embrace the idea that Earth was cooling and contracting, like a dried apple. Wegener's continental drift theory was not well received; some geologists were downright acrimonious. So, for nearly 50 years Wegener's continental drift languished, although a few prominent geologists were open to the idea, such as Franz Kossmat and Arthur Holmes. In fact, Holmes (1931) suggested the idea of mantle convection as the motive force for continental drift, which was later adopted in the mid-twentieth century revision of Wegener's theory that became known as the plate tectonics theory. In Holmes' mantle convection idea (Fig. 1), the rocky part of the Earth is assumed to circulate in great loops, like endless conveyor belts, dragging the continents along.

Before World War II relatively little was known about the land beneath the oceans. Submarine mountains had been discovered in the middle of the Atlantic Ocean, but the extent of the mid-ocean ridges, as they are now called, only became apparent from echo-sounding measurements made after that war: Now it is known that the global system of mid-ocean ridges encircles the Earth, like the stitching on a baseball, and forms a global chain of active volcanoes.

During World War II, Harry H. Hess, Captain of the U.S.S. Cape Johnson, an assault transport, let his vessel's echo-sounding equipment run continuously during long traverses across the Pacific Ocean. Hess was thus able to reveal the profiles of extensive tracts along the Pacific Ocean's floor. Hess discovered in the South Pacific flattopped undersea mountains that he named guyots. He 


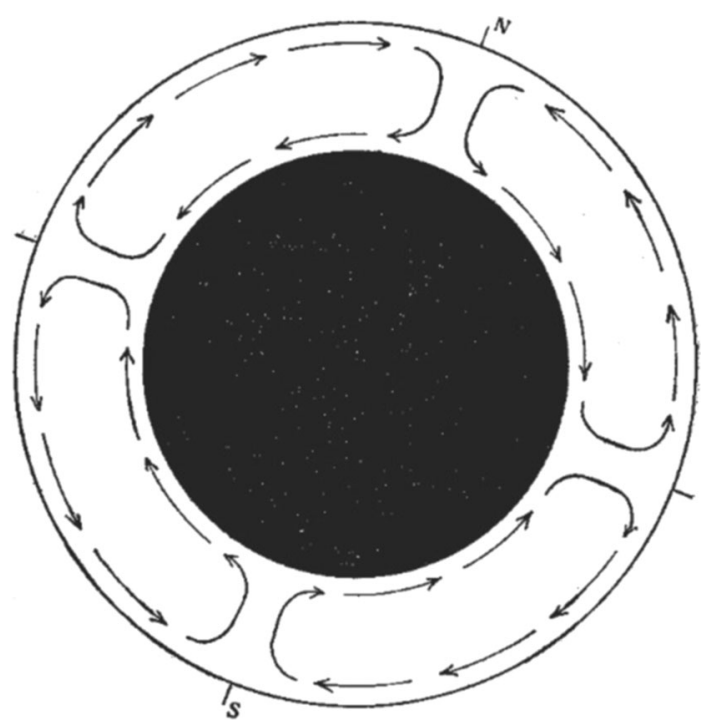

Fig. 1 Schematic representation of mantle convection published in 1931 by Holmes (1931). Reproduced with permission of the Geological Society of Glasgow

realized that these were originally volcanic mountains whose heights over time eroded first to sea level where they existed for a time as the support base for coral atolls. Slowly, the movement of the seafloor to which they were attached brought them into deeper water where they were submerged and finally brought them to the edge of a trench into which they would ultimately plunge. Reflecting on those observations, Hess (1954) proposed the concept of seafloor spreading, the idea that oceanic basalt, the rock comprising seafloors, continually erupts from volcanoes at the mid-ocean ridges, creeps across the ocean bottom, and ultimately plunges into the Earth at trenches that often occur beside the continents. Hess adopted Holmes' idea of mantle convection to explain the fate of subducted seafloor.

Hess' observation of seafloor spreading was confirmed by observations of seafloor magnetic stripes of alternating polarity symmetric on either side of mid-ocean ridges (Vine and Matthews 1963). Wegener's continental drift theory was thus resurrected and recast as plate tectonics theory, which included mantle convection as a critical component. Plate tectonics theory, which has dominated geological thinking for the past five decades, seemed to offer explanations for much of the surface geology of our planet, and for the scientific basis that underlies the geology of petroleum and natural gas deposit origination. So, what's wrong with this picture?

Plate tectonics seemed to explain so well a plethora of geological observations that many thought that mantle convection 'must' exist. Modeling mantle convection became a 'cottage industry'; numerous papers and even books were published on the subject. Yet, in five decades no independent, conclusive, corroborating evidence of mantle convection has emerged. So, I asked the question, "What's wrong with this picture?"

Convection is a familiar process: Heat a pot of water on the stovetop. Add a few tea leaves. Notice that just before boiling the tea leaves are carried along by the water moving from bottom to top and from top to bottom. Convection occurs because the warmer water at the bottom expands a bit, becoming less dense than the water at the top. This is an unstable top-heavy situation that seeks to correct itself by fluid motions. It is easy for one to imagine the mantle is undergoing a similar process; and that is what the scientific community did for half a century. However, I discovered, that is not correct. Why? The problem is that convection within the mantle is physically impossible (Herndon 2011). Compression by the weight of mass above causes the mantle bottom to be about $62 \%$ denser than the mantle top (Dziewonski and Anderson 1981). The small amount of thermal expansion, $<1 \%$, cannot lower the density of a parcel of bottom-mantle matter sufficiently so as to allow it to float to the mantle top. Sometimes in mantle convection models, the bottom-heavy prohibition is obviated by assuming that the solid rock mantle behaves as an ideal gas, adiabatic without viscous losses. But the mantle is not without viscous losses, as indicated by earthquakes at depths as great as $660 \mathrm{~km}$ (Ai et al. 2003). Moreover, the Rayleigh Number, derived for a non-compressed thin film (Rayleigh 1916), has been misapplied to wrongly justify physically impossible mantle convection. Without mantle convection, plate tectonics is not a valid geodynamic theory. Consequently, one must expect the existence of a more fundamental geodynamic theory, capable of explaining geological observations at least as well as plate tectonics, but which does not require or depend upon mantle convection.

\section{Whole-Earth decompression dynamics}

The currently popular concept of Earth's origin, the socalled 'standard model of solar system formation', developed contemporaneously with plate tectonics. This is the idea that dust condensed from a gas of solar composition at very low pressures, ca. $10^{-4}$ atmospheres (Cameron 1963), then gathered into progressively larger masses-grains, then rocks, boulders, planetesimals, and finally planets (Goldrich and Ward 1973; Wetherill 1980). Here is another chance to ask the question, "What's wrong with this picture?" and, I did. That is an incorrect concept of Earth's formation for the following reason: From thermodynamic considerations I discovered that the iron condensate from primordial solar matter at such low pressures would be oxidized, leading to insufficiently massive cores, which is contrary to observations of massive-core planets (Herndon 
2006d, 2013). Consequently, one must expect the existence of a more fundamental Earth-formation theory that is not contrary to observations.

Eucken (1944) considered the thermodynamics of Earth formation by condensing and raining-out within a giant gaseous protoplanet at pressures of 100-1000 atmospheres. He showed that at such pressures iron would condense as a liquid to form the core, followed by condensation of the silicate mantle. By similar, extended calculations, I verified Eucken's results and deduced that the oxygen-starved, highly reduced matter characteristic of enstatite chondrites and by inference the Earth's interior condensed from primordial solar system gas under circumstances that isolated the condensate from further reaction with the gas at low temperatures (Herndon 2006d; Herndon and Suess 1976). Earth's complete condensation, I theorized, formed a gasgiant planet virtually identical in mass to Jupiter, with a central rocky kernel compressed by 300 Earth-masses of gases and ices to approximately $66 \%$ of the diameter of present Earth (Herndon 2005, 2006d, 2009a, 2013). The plausibility of our rocky planet having originally formed as the rocky core of a Jupiter-like gas giant is demonstrated by the calculated model-density of the rocky portion of Jupiter being similar to the average calculated volumetric density of un-decompressed Earth surrounded by a closed contiguous shell of continental rock without ocean basis (Herndon 2006d). As the Sun ignited, T-Tauri outbursts stripped Earth of its giant gas/ice shell (Fig. 2).

The Archean began with Earth thus compressed, its surface, devoid of ocean basins, consisted of a closed, contiguous shell of continental rock. I call this unitary continent Ottland in honor of Ott Christoph Hilgenberg who first conceived of its existence (Hilgenberg 1933).

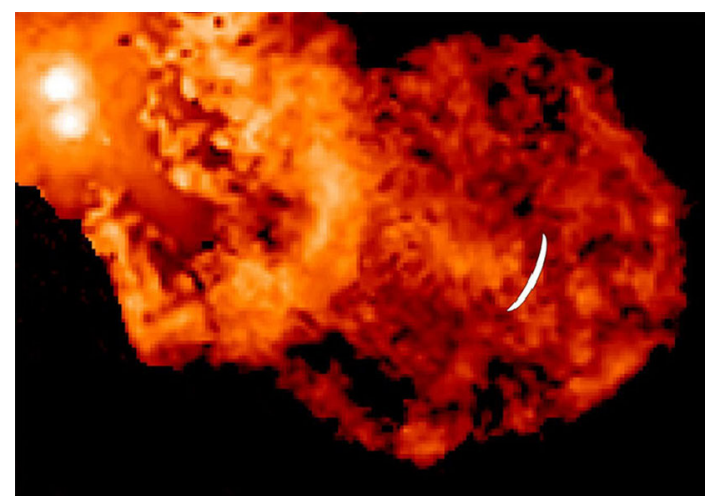

Fig. 2 Hubble Space Telescope image of binary star XZ-Tauri in 2000 showing a T-Tauri phase outburst. The white crescent label shows the position of the leading edge of that plume in 1995, indicating a leading-edge advance of 130 A.U. in 5 years. T-Tauri eruptions are observed in newly formed stars. Such eruptions from our newly formed Sun, I submit, stripped the primordial gases from the inner four planets of our Solar System
Over time, internal pressures began to build, but Earth could not begin to decompress and relieve pressure until its hard rocky surface shell started to crack. After the first formation of a surface crack, Earth began to decompress. The initial decompression rate, after the first crack formation, must have been considerably higher than at present which, based upon volumetric basalt extrusion, is currently quite low (Herndon 2006d). The manner of that decompression is the basis for a new indivisible geoscience paradigm that I refer to as whole-Earth decompression dynamics (WEDD): the fundamental basis of geology and geodynamics (Herndon 2005, 2006d, b, 2009a, 2013).

As Earth decompresses, driven primarily by the stored energy of protoplanetary compression and augmented by nuclear fission and radioactive decay energy (Herndon 2003, 2007, 2014), our planet increases in diameter. The manner of surface response to increased diameter is the principal basis of geomorphology.

As planetary volume increases, the surface area increases by rifting, the formation of cracks, some with underlying heat sources (primary), and some without (secondary). Basalt extruded from a primary crack creeps by gravity across the surface until encountering, falling into and infilling a secondary crack. This is the behavior manifest at mid-ocean ridges, and it explains submarine topography and seafloor magnetic striations without necessitating physically impossible mantle convection. Rifting, the formation of cracks in response to planetary volume increases is responsible for the progressive fragmentation of the surface crust into continents. This process is currently ongoing along the East African Rift System where it produced Lake Tanganyika with a depth of 1.47 km. Similarly, Lake Baikal in Russia, depth 1.64 km, was rift formed. The circum-pacific trenches, I posit, are secondary decompression cracks with depths in the range 7.5-10.9 km.

As planetary volume increases, surface curvature must change. Consider a hypothetical circular section of ancient continental crust placed atop a later, more decompressed, larger Earth, as illustrated by the demonstration shown in Fig. 3. Note that the section of ancient crust contains within its perimeter 'excess' surface area that must be 'removed' for the ancient section to adjust to the new curvature. I have suggested that mountains characterized by folding originate as the decompression-consequence of Earth's surface adjusting its curvature to conform to the curvature needed for a different, greater radius (Herndon 2012). As a result of decompression, the 'extra' surface area, constrained within a continental perimeter, buckles, breaks, and falls over producing fold-mountains, and thus better conforms to the more-decompressed Earth curvature.

Globally, virtually all major geological activity related to petroleum and natural gas deposits is the consequence of 


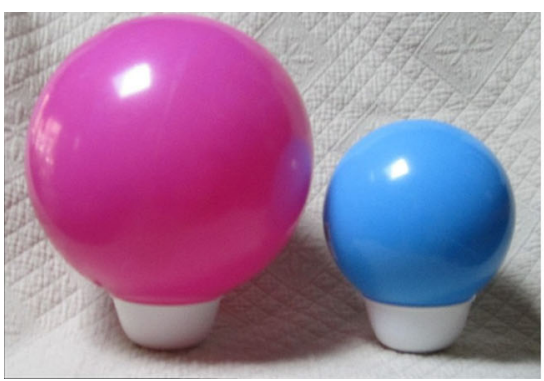

Fig. 3 Demonstration illustrating the formation of fold-mountains as a consequence of Earth's early formation as a Jupiter-like gas giant (Herndon 2012). On the left, two balls representing the relative proportions of 'present' Earth (pink), and 'ancient' Earth (blue) before decompression. In the center, a spherical section, representing a continent, cut from 'ancient' Earth and placed on the 'present' Earth, showing: (1) the curvature of the 'ancient continent' does not match

new surface area formation to accommodate decompression-increased planetary volume, which primarily involves crustal extension fracturing, basalt extrusion, and decompression crack in-filling. Although the driving force for Earth's decompression is primarily expressed as torsional forces at the surface, lateral forces also occur as a consequence of the non-symmetric rifting of the solid crust and the tendency of the surface plates to minimize associated surface energy (Herndon 2005, 2006a). The principal energy for geological and geodynamic activity is the enormous energy of protoplanetary compression that was stored when the rocky-Earth was compressed to about $66 \%$ of present diameter by approximately 300 Earthmasses of primordial gases and ices. That energy source for geological and geodynamic activity is augmented to some extent by georeactor nuclear fission energy and by radioactive decay energy (Herndon 2011, 2014).

Mantle decompression will tend to propagate throughout the mantle, like a tsunami, until it reaches the impediment posed by the base of the crust. There, crustal rigidity opposes continued decompression; pressure builds and compresses matter at the mantle-crust-interface, resulting in compression heating. Ultimately, pressure is released at the surface through primary decompression crack formation, i.e., extension fracturing with its associated basin formation and volcanism, and through secondary decompression crack formation and/or enlargement. The process of mantle decompression thermal-tsunami may account for much of the heat leaving the Earth's surface, for the geothermal gradient observed in the crust, for substantial volcanism and for earthquake generation as well (Herndon 2006a). That process also might greatly enhance the prognosis for future abiotic energy supplies by pressurizing and heating the base of the crust, a potential collection point for mantle methane or other carbonaceous matter (Herndon 2006c). One consequence of my discovery of the

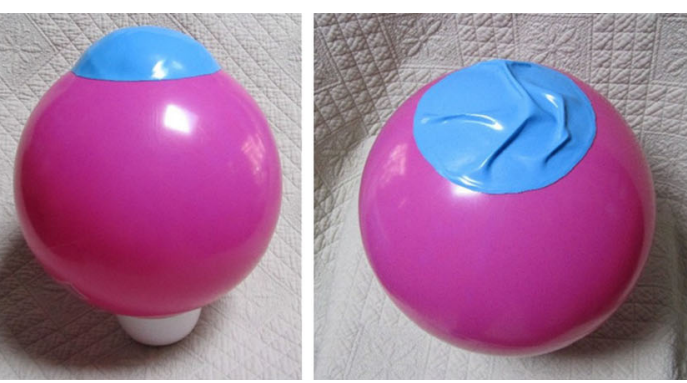

the curvature of the 'present' Earth and (2) the 'ancient continent' has 'extra' surface area confined within its fixed perimeter. On the right, tucks remove 'extra' surface area and illustrate the process of foldmountain formation that is necessary for the 'ancient' continent to conform to the curvature of the 'present' Earth. Unlike the ballmaterial, rock is brittle so tucks in the Earth's crust would break and fall over upon themselves producing fold-mountains

physical impossibility of mantle convection (Herndon 2009 b) is the realization that the whole-Earth decompression and the phenomena previously called "mantle plumes" are intimately and actively connected.

In the 1960s, geoscientists discovered occluded helium in oceanic basalt which remarkably possesses a higher ${ }^{3} \mathrm{He} /{ }^{4} \mathrm{He}$ ratio than air. At the time there was no known deep-Earth mechanism that could account for the experimentally measured ${ }^{3} \mathrm{He}$, so its origin was assumed to be a primordial ${ }^{3} \mathrm{He}$ component, trapped at the time of Earth's formation, which was subsequently diluted with ${ }^{4} \mathrm{He}$ from radioactive decay. State-of-the-art numerical simulations of georeactor operation, conducted at Oak Ridge National Laboratory, yielded fission-product helium, as shown in Fig. 4, with isotopic compositions within the exact range of compositions typically observed in oceanic basalts (Herndon 2003; Hollenbach and Herndon 2001). For additional information, see Rao (2002).

Forty-nine purported hot-spots have been identified, but not all have identical surface or compositional manifestations (Coutilot et al. 2003). About $18 \%$ of those, including the Hawaiian Islands and Iceland, are characterized by basalts containing helium with high ${ }^{3} \mathrm{He} /{ }^{4} \mathrm{He}$ ratios, i.e., $R_{\mathrm{A}}>10$. Beneath both Hawaii and Iceland, seismic tomography images plume-like structures which extend downward to the base of the lower mantle (Bijwaard and Spakman 1999; Ji and Nataf 1998; Nataf 2000). Because mantle convection is physically impossible (Herndon 2009b), these structures cannot be plumes, not matter transported by buoyancy from the bottom of the lower mantle to the surface. Instead, these appear to be thermal in origin, paths where heat from the Earth's core channels to the surface. Water, uniformly distributed upon soil, often peculates downward by gravity in a non-uniform way, forming channels through paths of less resistance. An analogous process might occur in Earth's mantle for the 


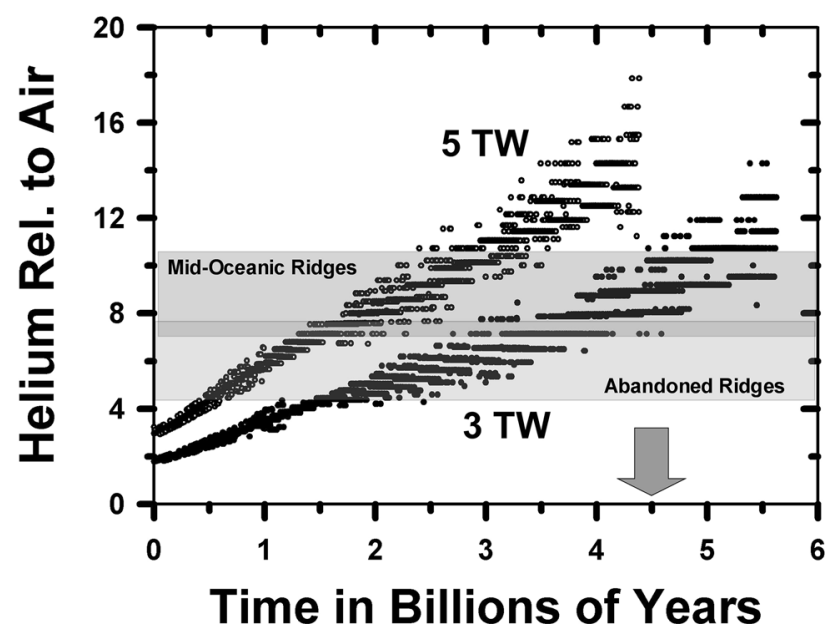

Fig. 4 Fission product ratio of ${ }^{3} \mathrm{He} /{ }^{4} \mathrm{He}$, relative to that of air, $R_{\mathrm{A}}$, from nuclear georeactor numerical calculations at $5 \mathrm{TW}$ (upper) and 3 TW (lower) power levels (Herndon 2003). The band comprising the $95 \%$ confidence level for measured values from mid-oceanic ridge basalts (MORB) is indicated by the solid lines. The age of the Earth is marked by the arrow. Note the distribution of calculated values at 4.5 Gyr, the approximate age of the Earth. The increasing values are the consequence of uranium fuel burn-up. Iceland deep-source "plume" basalts present values ranging as high as $37 R_{\mathrm{A}}$ (Hilton et al. 1999). Figure from (Herndon 2008)

upward channeling of heat. Innumerable layers of buoyancy-driven micro-convection in conjunction with conduction may operate to directionally bias and/or augment the flow of core-derived heat upward to regions of lesser density (Herndon 2011).

Helium, being a very light, highly mobile, inert, unreactive, fast-moving gas, apparently can travel from Earth's core to surface through these heat conduits, progressing upward toward ever-decreasing densities. In addition to portending the eventual demise of the geomagnetic field (Herndon 2003), the high ${ }^{3} \mathrm{He} /{ }^{4} \mathrm{He}$ ratios observed serve as markers, identifying the particular basalt as one whose extrusion involved thusly channeled Earth-core heat.

Rather than basalt extrusion occurring simply as seafloor passes over a hot-spot, global-scale whole-Earth decompression appears to be intrinsically involved, at least in instances where Earth-core channeled heat can be identified by high ${ }^{3} \mathrm{He} /{ }^{4} \mathrm{He}$ ratios. Mjelde and Faleide (2009) have discovered, for example, variations in Icelandic basalt production which have the same periodicity and relative timing as Hawaiian basalt variations on the opposite side of the Earth. Their discovery may have broad, but yet unappreciated implications.

Seafloor passing over hot-spots offers a reasonable explanation for the formation of basaltic island arcs, such as the Hawaiian Islands and the associated Emperor Seamount chain. Significantly, that explanation is in accord with whole-Earth decompression dynamics. The generalization of the 'passing over a hot-spot' concept to mid-continental basalt floods, such as the Siberian Traps in central Russia, which has high ${ }^{3} \mathrm{He} /{ }^{4} \mathrm{He}$ ratios (Basu et al. 1993, 1995), though, is problematic from the standpoint of plate tectonics (Herndon 2009b).

The ancient super-continent, Pangaea, envisioned by Wagener (1912) and adopted in plate tectonic considerations, was thought to be surrounded by ocean occupying nearly $1 \frac{1}{2}$ times its surface area. The ancient super-continent envisioned in whole-Earth decompression dynamics (Herndon 2005, 2006a) originally occupied $100 \%$ of the Earth's surface with the Earth's radius being about $66 \%$ of its current value. In the broad picture, for present-day continents to have attained their current locations, continent fragmenting, and successive fragmenting, took place by extension fracturing and the subsequent formation of secondary decompression cracks and their in-filling with extruded basalt, which increased Earth's surface area and the formed the ocean basins. The detailed picture, undoubtedly, was more complex due to competitive interactions.

\section{Origin of oil and gas deposits}

India can be understood geologically as a continent in the process of fragmenting, the specifics of which are described in detail by Sheth (2005), from which Fig. 5 is adapted. Note the numerous 'rifts' indicated in that schematic representation of India. In plate tectonics terminology, 'rift' refers to the interface of two plates that are beginning to pull apart. In whole-Earth decompression dynamics, 'rift' refers to the beginning of the formation of a decompression crack.

Rifting is an integral part of the whole-Earth decompression process of successive continental fragmenting about which I make the following generalizations: The process of continental fragmenting begins with the formation of a decompression crack. Over time, the crack widens, forming a rift-valley or basin. Volcanic eruptions may subsequently occur, depending mainly upon available heat. The rift-basin thus formed becomes an ideal environment for the development of geological strata frequently associated with petroleum and natural gas deposits, such as sandstone layers, and can remain a part of the continental margins even after ocean-floor formation. Such ancient rift-basin formations, commonly referred to as sedimentary basins in the oil industry, are the targets for petroleum and natural gas exploration worldwide.

Figure 5, the schematic representation of India adapted from Sheth (2005), emphasizes India's numerous major rifts. I have added to that figure in red the locations where major petroleum and natural gas discoveries have been 
Fig. 5 Schematic representation of India, adapted with permission from Sheth (2005), showing rift zones crossing peninsula India and showing the present outcrop areas of the Deccan and Rajmahal flood basalts (shaded). Areas where significant petroleum and natural gas discoveries have been made are shown in red. Not to scale

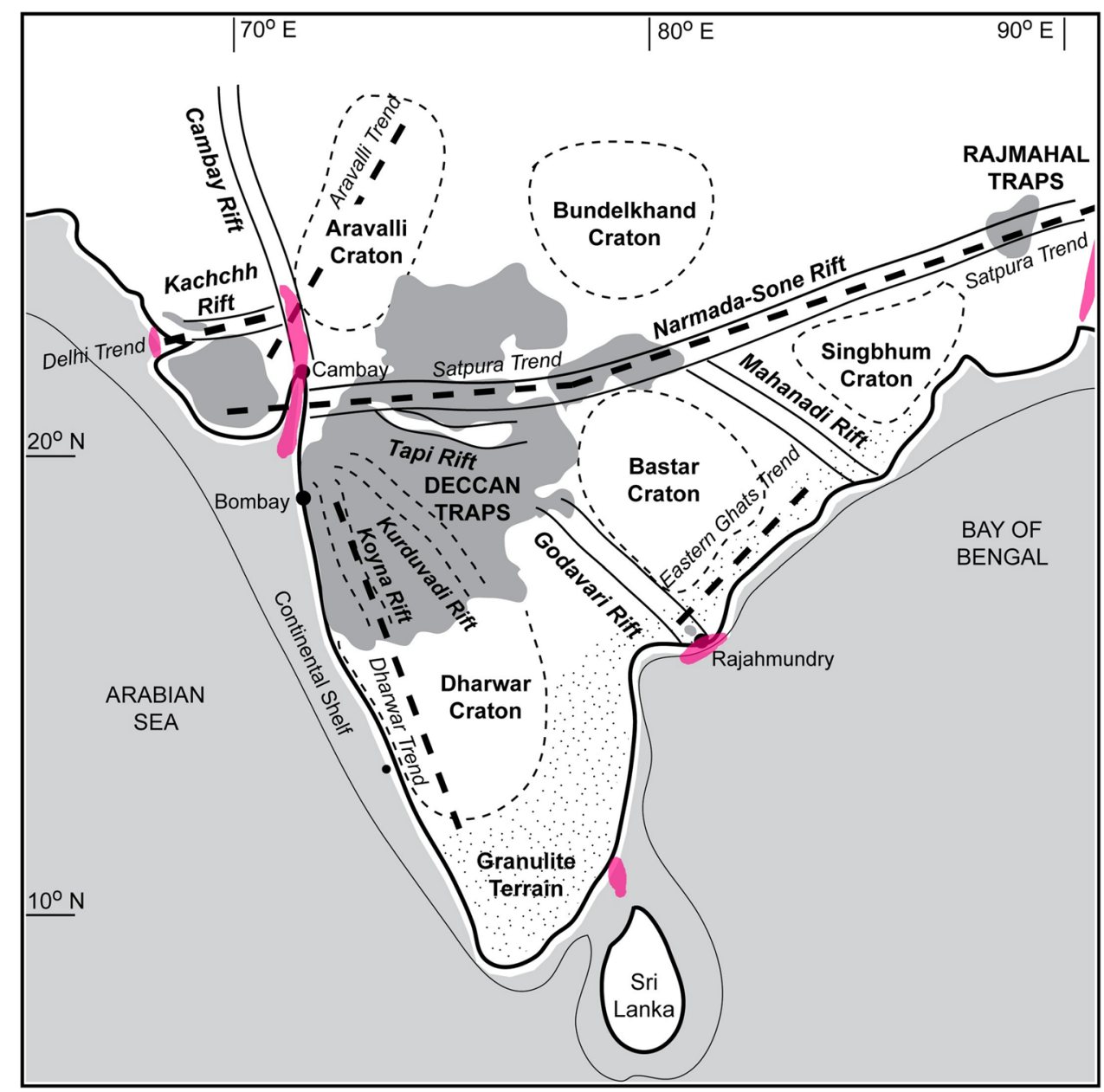

made. Not surprisingly, the petroleum and natural gas discoveries seem to be closely associated with rift areas. Rift-basin formations tend to develop geological strata conducive for trapping petroleum and natural gas. A fundamental question arises as to whether the petroleum and natural gas occluded there is exclusively biogenic in origin, or whether abiotic methane and hydrocarbons, seeped from the Earth's mantle through those rifts, are trapped there as well and to what degree. Certainly, in a global sense, there is reason to suspect potential association of rift-basin formation and mantle methane availability.

For nearly five decades, petroleum exploration geology has been described in terms of plate tectonics, which is based upon physically impossible mantle convection. Surface manifestations, such as foreland basins and backarc basins, which seem well-described by plate tectonics, are in many instances similarly described by whole-Earth decompression dynamics, although with subtle, but important, differences, especially those related to the absence of subduction.

Rifting is an integral part of the whole-Earth decompression process of successive continent fragmenting, beginning with Ottland and continuing into the present, and about which I make the following generalizations: The process of continent fragmenting begins with the formation of a decompression crack. Over time, the crack widens, forming a rift-valley or basin. Volcanic eruptions may subsequently occur, depending mainly upon available heat. The rift-basin thus formed becomes an ideal environment for the development of geological strata frequently associated with petroleum and natural gas deposits and can remain a part of the continental margins even after oceanfloor formation.

Virtually, all petroleum deposits are connected in some way to, or are the consequence of, rifting, even those deposits, such as foreland basins, that involve underthrust compression, which may result from rifting and extension elsewhere. Continent fragmenting, both successful and failed, initiates with rifting. Observations of rifting which is currently taking place at the Afar triangle in northeastern Ethiopia, and observations of the consequences of rifting throughout the East African Rift System (Fig. 6) can help to shed light on the nature of petroleum-deposit-related rifting that has occurred elsewhere. 


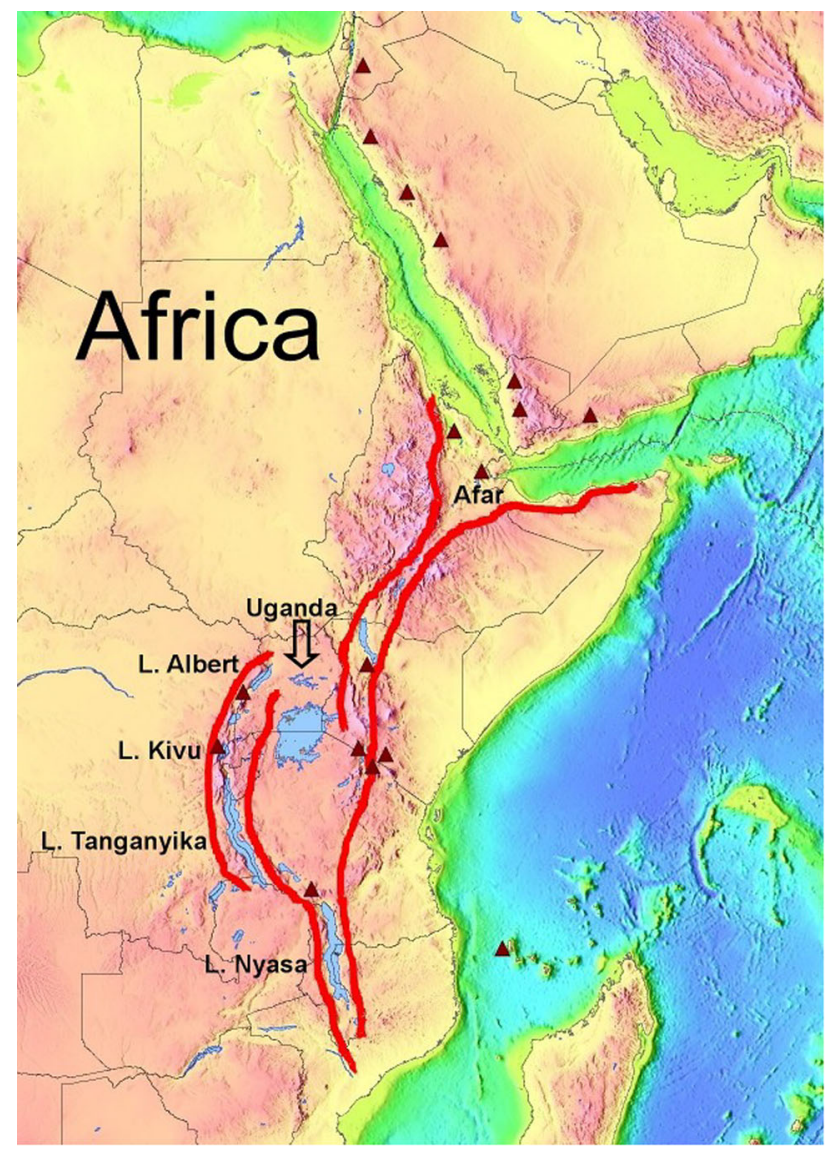

Fig. 6 Northeastern portion of Africa. Red lines show the major rifts comprising the East African Rift System. Active volcanoes are indicated by maroon triangles

The Afar triangle is the triple junction where the Red Sea rift, the Carlsberg Ridge of the Indian Ocean, and the East African Rift System meet. Seismic tomographic imaging beneath that region shows a very large, low-velocity zone extending to the base of the lower mantle, referred to as a "superplume" (Zhao 2001; Ni et al. 2002). Since heat at the base of the lower mantle cannot make bottom-mantle matter sufficiently buoyant to float upward (Herndon 2011), the high ${ }^{3} \mathrm{He} /{ }^{4} \mathrm{He}$ ratios, $R_{\mathrm{A}}>10$, measured in Afar volcanic basalt (Marty et al. 1993), indicate mantle-deep heat channeling, which allows the highly mobile, inert helium to migrate upward toward regions of progressively lower density.

The extension-related processes observed at Afar and along the East African Rift System provide all of the crucial components for petroleum deposit formation. Rifting causes the formation of deep basins, as evidenced, for example, by Lake Tanganyika, depth $1.4 \mathrm{~km}$, the second deepest lake in the world, and by Lake Nyasa, depth $0.7 \mathrm{~km}$, the fourth deepest lake, both of which occur as part of the East African Rift System. The observed uplifting caused by swelling from below
(Almond 1986) makes surface land susceptible to erosion, thus providing great amounts of sedimentary material for reservoir rock in-filling of basins. Volcanic-derived sedimentary material may be richly mineralized, assuring strong phytoplankton blooms. Uplifting can sequester seaflooded lands thus leading to the formation of marine halite deposits through desiccation and can also lead to dome formation as well.

Afar swelling is important in providing sediments for reservoir sands, delivered by the Congo, Niger and Nile rivers, to continent-edge basins, which were formed during earlier continent fragmenting by extension and which are Africa's main petroleum provinces. All of the components of reservoir, source and seal are related to the influx of sediments (Burke et al. 2003). Local rifting can provide all those components, as well as basin formation, as indicated by a report published in June 2, 2009 by East African Business Week, which notes that, based upon recent testwell results, a senior official of the U. S. Department of Energy indicated that Uganda's [Lake Albert basin of the East African Rift System] oil reserves could be as much as that of Persian Gulf countries.

Also, what of the possibility of abiotic petroleum? Although there is not yet an unambiguous way to ascertain the extent to which petroleum might be of abiotic origin, the possibility, though controversial, should not be dismissed, especially in circumstances where rifting is involved. For example, Gold and Soter (1980) stated that Lake Kivu, part of the East African Rift System, contains 50 million tons of dissolved methane for which there is no adequate microbial source.

The West Siberial Basin, host to some of the world's greatest petroleum and natural gas deposits, traditionally has been assumed in plate tectonics to have resulted during the formation of the Ural mountains which are assumed to have formed as the European plate supposedly collided with the Asian plate during the formation of Pangaea. But the underpinning of plate tectonics, i.e., mantle convection, is physically impossible, meaning that continents are not free to move about; thus, there must exist another more fundamental explanation.

The region including the West Siberian Basin, located between the Ural Mountains and the Siberian Platform, and the Siberian Platform underwent extensive rifting about 500-250 Myr ago, leading to rift-basin formations that developed geological strata on a grand scale, extremely conducive for trapping petroleum and natural gas (Reichow et al. 2002). About $250 \mathrm{Myr}$ ago, massive basalt floods spewed forth for about one million years blanketing the area with perhaps more than $2000 \mathrm{~km}^{3}$ of basalt containing helium having high ${ }^{3} \mathrm{He} /{ }^{4} \mathrm{He}$ ratios (Basu et al. 1995). These are the Siberian Traps. Evidence indicates that rifting continued after basalt extrusion (Reichow et al. 2002). 
Rifting appears to underlie the formation of rift basins and later the massive eruption of basalt. The high ${ }^{3} \mathrm{He} /{ }^{4} \mathrm{He}$ ratios indicate that heat was channeled from the Earth's core (Herndon 2011). Today, that area is known to contain some of the most extensive petroleum, natural gas, and coal deposits in the world.

Figure 7 is a map showing the extent of the Siberian Traps. I added to that map the sites of major oil and gas wells (Horn 1983). The overwhelming proportion of indicated gas and oil fields contained within the Siberian Traps region suggests a causal relationship: Decompression-driven rifting, especially when associated with georeactorproduced heat channeled from the Earth's core, is the principal basis for the origination of petroleum and gas deposits.

About 1100 million years ago, rifting occurred on a grand scale in the middle of what is now the North American continent. The Mid-Continental Rift System or Keweenawan Rift, as it is called, began to split the surface for a length of about $2000 \mathrm{~km}$. In a manner similar to Afar and the East African Rift System, a hotspot presumably produced a large dome, massive lava flows erupted from the central axis of the Keweenawan Rift, thick sedimentary deposits were emplaced which includes a massive oil-shale layer. As with the Siberian Traps, rifting ceased before it formed a new ocean basin.

Sheth (2005) set forth compelling evidence that India's Deccan Traps originated by rifting. The consequence of rifting is the formation of rift valleys and rift basins, which over geological time may develop into sedimentary basins with geological strata favorable to the entrapment of petroleum and natural gas. Like the Siberian Traps, the Deccan Traps are the consequence of massive flood basalt eruptions about $65 \mathrm{Myr}$ ago which blanketed the underlying geological features. Also, like the Siberian Traps, the high ${ }^{3} \mathrm{He} /{ }^{4} \mathrm{He}$ ratios observed in Deccan basalt are indicative of the heat having been channeled from the Earth's core (Basu et al. 1993). From the standpoint of the reasoning developed in the scientific article upon which this chapter is based (Herndon 2010), from the generality of the considerations involved, and from the experience garnered from the larger and older Siberian Traps, I predicted by that, as in the Siberian example, the region beneath India's Deccan Traps may well host potentially great petroleum and natural gas deposits. And, indeed, the evidence to date seems to support that conjecture.

An article in The Economic Times (1 May 2008), announced the discovery by ONGC of petroleum and
Fig. 7 Map, courtesy of Jo Weber, showing the extent of the Siberian Traps as based upon estimates derived from Masaitis (1983). Circles show major gas fields; diamonds show major oil fields; data from Horn (1983)

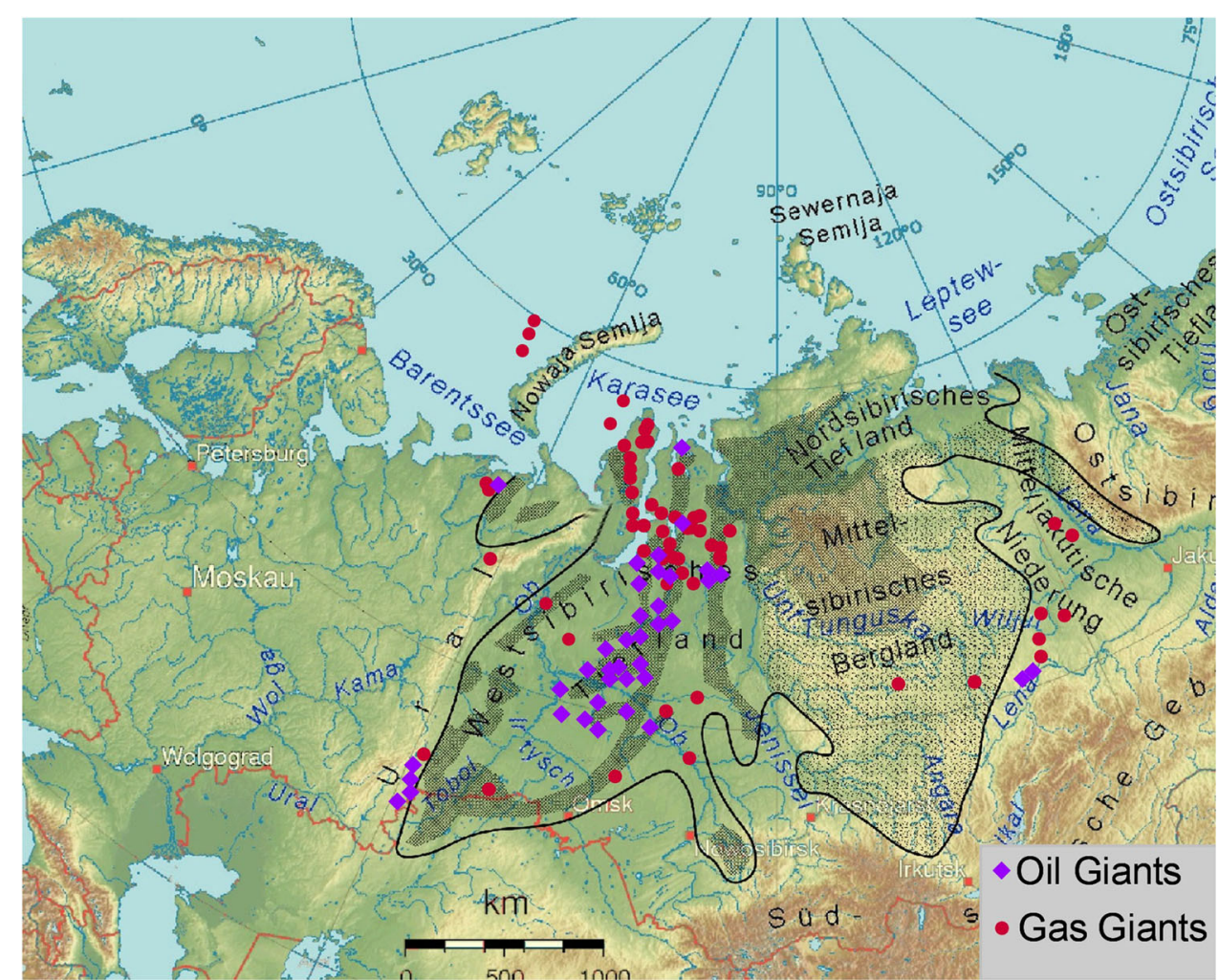


natural gas beneath the Deccan Traps. Moreover, there has been a concerted effort by scientists who have discovered surface evidence of hydrocarbons beneath the Deccan Traps (Dayal et al. 2008, 2009; Rasheen et al. 2012).

The following conclusions were presented at a 2013 conference sponsored by the Society of Petroleum Geophysicists, India (Jamkhindikar et al. 2013): (1) Oil bearing zones are interpreted in 6 wells in the area in Deccan Trap based on oil shows during drilling/interpretation of $\log$ motifs; (2) one well has produced commercial quantity of oil during initial production testing after lowering casing and perforating a $4 \mathrm{~m}$ zone in fractured basalt near top of Deccan Trap; (3) one nearby well in Unawa area is producing oil from Deccan Trap for the last 24 years which conclusively proves prospectivity of Deccan Traps in this part of the basin; (4) Deccan Traps can be identified from well $\operatorname{logs}$ and Micro-resistivity borehole images; (5) it is sometimes difficult to distinguish Deccan Traps from overlying Olpad formation from drill cuttings as highly altered basalt results in clays, so cuttings of Deccan Trap are described as trap derivatives/clay. The top of Deccan Traps could be successfully traced on 2D and 3D seismic lines, particularly in shallower part of the block; (6) integration of micro-resistivity borehole images and formation pressure test results point toward existence of primary (vesicular) porosity and secondary (fracture) porosity in Deccan Traps. Also, presence of mega-vesicles seen on borehole images of some wells and resistivity logs showing good invasion profile indicates that vesicular zones can be good reservoirs; (7) fracture characterization based on micro-resistivity borehole images has brought out preferred fracture orientation at each well location. The fractures are generally related to faults as stress relieving antithetic fractures. These fractures can provide conduits for hydrocarbon charging through faults; and (8) the study of fault pattern in the area coupled with occurrence of oil bearing zones in the Deccan Trap suggests that the N-S and NESW trending faults are the main migratory pathways for oil. Thus, areas of local highs near these faults could be the main targets for exploration of Deccan Trap in northern part of Cambay Basin.

Generally, continent fragmenting, as the result of wholeEarth decompression and channeled heat from beneath, whether on-going, completed or arrested, leads to rift-basin formation, to surface uplift and doming, and to the formation of voluminous volcanic deposits. The geological consequences of which can provide all of the crucial components for petroleum and natural gas deposits: basin, reservoir, source and seal. Not surprisingly, much oil and gas exploration activities are focused along continental margins where fragmenting and presumably petroleum deposit formation has taken place. Thus, the discovery of previously unrecognized rift valleys may harbor new petroleum and natural gas exploration possibilities.

\section{Conclusions}

Whole-Earth decompression dynamics (WEDD) is a new geodynamic theory that stems from Earth's early formation as a Jupiter-like gas giant. Following removal of its massive Jupiter-like gas/ice envelope, the rocky-Earth, compressed to about $66 \%$ of present diameter, was completely covered by a closed continental-rock shell. Decompression-driven rifting, a crucial action for increasing surface area and for petroleum deposit formation, begins with the formation of a decompression crack. Over time, the crack widens, forming a rift-valley or basin. Uplifting associated with rifting, caused by swelling from below, makes surface land susceptible to erosion, thus providing great amounts of sedimentary material for sandstone layers and for reservoir rock in-filling of basins. Uplifting can sequester sea-flooded lands thus leading to the formation of marine halite deposits through desiccation and can lead to dome formation as well. Volcanic eruptions may subsequently occur, depending mainly upon available heat. The rift-basin thus formed becomes an ideal environment for the development of geological strata frequently associated with petroleum and natural gas deposits and can remain a part of the continental margins even after ocean-floor formation. Hence, continental margins are exploration targets. Ancient rift-basin formations, commonly referred to as sedimentary basins in the oil industry, likewise are targets for petroleum and natural gas exploration worldwide.

Decompression-driven rifting, especially when associated with georeactor-produced heat channeled from the Earth's core, is the principal basis for the origination of petroleum and gas deposits. That association is evident in the West Siberian Basin, the East African Rift System, the Mid-Continental Rift System or Keweenawan Rift, and elsewhere. That association is proposed to have occurred beneath the Deccan Traps in India.

Although there is question as to whether the petroleum and natural gas occluded is exclusively biogenic in origin, or whether abiotic methane and hydrocarbons, seeped from the Earth's mantle through those rifts, are trapped there as well and to what degree. Nevertheless, there is reason to suspect potential association of decompression-driven riftbasin formation and mantle methane availability.

Open Access This article is distributed under the terms of the Creative Commons Attribution 4.0 International License (http:// creativecommons.org/licenses/by/4.0/), which permits unrestricted use, distribution, and reproduction in any medium, provided you give appropriate credit to the original author(s) and the source, provide a 
link to the Creative Commons license, and indicate if changes were made.

\section{References}

Ai Y, Zheng T, Xu W, He Y, Dong D (2003) A complex 660 km discontinuity beneath northeast China. Earth Planet Sci Lett 212:63-71

Almond DC (1986) Geological evolution of the Afro-Arabian dome. Techtonophys 331:302-333

Basu AR, Renne PR, DasGupta DK, Teichmann F, Poreda RJ (1993) Early and late alkali igneous pulses and a high- ${ }^{3} \mathrm{He}$ plume origin for the Deccan flood basalts. Science 261:902-906

Basu AR, Poreda RJ, Renne PR, Teichmann F, Vasiliev YR, Sobolev NV, Turrin BD (1995) High- ${ }^{3} \mathrm{He}$ plume origin and temporalspacial evolution of the Siberian flood basalts. Science 269:825-882

Bijwaard H, Spakman W (1999) Tomographic evidence for a narrow whole mantle plume below Iceland. Earth Planet Sci Lett 166:121-126

Brown LA (1979) The story of maps. Dover Publications Inc, New York

Burke K, MacGregor DS, Cameron NR (2003) Africa's petroleum systems: four tectonic 'Aces' in the past 600 million years. In: Arthur T, MacGregor DS, Cameron NR (eds) Petroleum geology of Africa: new themes and developing technologies, vol Special Publication vol No. 207. Geological Society, London, pp 21-60

Cameron AGW (1963) Formation of the solar nebula. Icarus $1: 339-342$

Coutilot V, Davaille A, Besse J, Stock J (2003) Three distinct types of hotspots in the Earth's mantle. Earth Planet Sci Lett 205:295-308

Dayal AM, Patil DJ, Raju SV (2008) Search of hydrocarbons in Mesozoic sediments below the Deccan basalt, India. Geochem Cosmochem Acta A 204:44

Dayal AM, Rasheed MA, Prassana V, Raju SV (2009) Geomicrobial prospecting for hydrocarbon research in Deccan Syneclise, India. Geochem Cosmochem Acta A 270:73

Dziewonski AM, Anderson DA (1981) Preliminary reference Earth model. Phys Earth Planet Inter 25:297-356

Eucken A (1944) Physikalisch-chemische Betrachtungen ueber die frueheste Entwicklungsgeschichte der Erde. Nachr Akad Wiss Goettingen, Math-K1, 1-25

Gold T, Soter S (1980) The deep Earth gas hypothesis. Bull Verein Schweiz Petroleum-Geologen und -Ingenieure 46:11-35

Goldrich P, Ward WR (1973) The formation of planetesimals. Astrophys J 183(3):1051-1061

Herndon JM (2003) Nuclear georeactor origin of oceanic basalt ${ }^{3} \mathrm{He} /{ }^{4} \mathrm{He}$, evidence, and implications. Proc Natl Acad Sci USA 100(6):3047-3050

Herndon JM (2005) Whole-Earth decompression dynamics. Curr Sci 89(10): 1937-1941

Herndon JM (2006a) Energy for geodynamics: mantle decompression thermal tsunami. Curr Sci 90:1605-1606

Herndon JM (2006b) Energy for geodynamics: mantle decompression thermal tsunami. Curr Sci 90(12):1605-1606

Herndon JM (2006c) Enhanced prognosis for abiotic natural gas and petroleum resources. Curr Sci 91(5):596-598

Herndon JM (2006d) Solar system processes underlying planetary formation, geodynamics, and the georeactor. Earth Moon Planets 99(1):53-99

Herndon JM (2007) Nuclear georeactor generation of the Earth's geomagnetic field. Curr Sci 93(11):1485-1487
Herndon JM (2008) Maverick's Earth and universe. Trafford Publishing, Vancouver

Herndon JM (2009a) Nature of planetary matter and magnetic field generation in the solar system. Curr Sci 96(8):1033-1039

Herndon JM (2009b) Uniqueness of Herndon's georeactor: energy source and production mechanism for Earth's magnetic field. arXiv:org/abs/09014509

Herndon JM (2010) Impact of recent discoveries on petroleum and natural gas exploration: emphasis on India. Curr Sci 98(6):772-779

Herndon JM (2011) Geodynamic basis of heat transport in the Earth. Curr Sci 101(11):1440-1450

Herndon JM (2012) Origin of mountains and primary initiation of submarine canyons: the consequences of Earth's early formation as a Jupiter-like gas giant. Curr Sci 102(10):1370-1372

Herndon JM (2013) New indivisible planetary science paradigm. Curr Sci 105(4):450-460

Herndon JM (2014) Terracentric nuclear fission georeactor: background, basis, feasibility, structure, evidence, and geophysical implications. Curr Sci 106(4):528-541

Herndon JM, Suess HE (1976) Can enstatite meteorites form from a nebula of solar composition? Geochim Cosmochim Acta 40:395-399

Hess HH (1954) Geological hypotheses and the Earth's crust under the oceans. Proc R Soc Lond A222:341-348

Hilgenberg OC (1933) Vom wachsenden erdball. Giessmann and Bartsch, Berlin

Hilton DR, Grönvold K, Macpherson CG, Castillo PR (1999) Extreme $\mathrm{He}-3 / \mathrm{He}-4$ ratios in northwest Iceland: constraining the common component in mantle plumes. Earth Planet Sci Lett 173(1-2):53-60

Hollenbach DF, Herndon JM (2001) Deep-Earth reactor: nuclear fission, helium, and the geomagnetic field. Proc Natl Acad Sci USA 98(20): 11085-11090

Holmes A (1931) Radioactivity and Earth movements. Trans Geol Soc Glasgow 1928-1929(18):559-606

Horn MK (1983) Giant fields 1869-2003. In: Halbouty MK (ed 2003) Giant oil and gas fields of the decade, 1990-1999. AAPG, Houston.

Jamkhindikar A, Jain M, Mohanty SN (2013) Hydrocarbon prospectivity of Deccan trap in Northern Cambay Basin. In: Paper presented at the 10th biennial international conference and exposition Kochi, India

Ji Y, Nataf H-C (1998) Detection of mantle plumes in the lower mantle by diffraction tomography: Hawaii. Earth Planet Sci Lett 159(3-4):99-115

Kuhn TS (1962) The structure of scientific revolutions. University of Chicago Press, Chicago

Marty B et al (1993) $\mathrm{He}$, Ar, $\mathrm{Nd}$ and $\mathrm{Pb}$ isotopes in volcanic rocks from Afar. Geochem J 27:219-228

Masaitis VL (1983) Permian and Triassic volcanism of Siberia. Zapiski VMO part CXII 4:412-425 (in Russian)

Mjelde R, Faleide JI (2009) Variation of Icelandic and Hawaiian magmatism: evidence for co-pulsation of mantle plumes? Mar Geophys Res 30:61-72

Nataf H-C (2000) Seismic imaging of mantle plumes. Ann Rev Earth Planet Sci 28:391-417

Ni S et al (2002) Sharp sides to the African superplume. Science 296:1850-1852

Rao KR (2002) Nuclear reactor at the core of the Earth! - a solution to the riddles of relative abundances of helium isotopes and geomagnetic field variability. Curr Sci 82(2):126-127

Rasheen MA, Kalpana MS, Prasanna MV, Lakshmi M, Madhavi T, Mani D, Patil AM, Dyal AM, Raju SV (2012) Geo-microbial and light gaseous hydrocarbon anomalies in near surface soils of

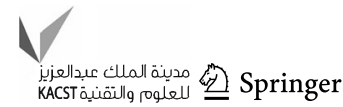


Deccan Syneclise Basin, India: implications to hydrocarbon resource potential. J Petrol Sci Eng 84-85:33-41

Rayleigh L (1916) On convection currents in a horizontal layer of fluid, when the higher temperature is on the under side. Philos Mag 32:529-546

Reichow MK, Saunders AD, White RW, Pringle MS, Al'Mukhamedov AI, Medvedev AI, Kirda NP (2002) ${ }^{40} \mathrm{Ar} /{ }^{39} \mathrm{Ar}$ dates from the West Siberian Basin: Siberian flood basalt province doubled. Science 296:1846-1849

Sheth HC (2005) From Deccan to reunion: no trace of a mantle plume. In: Foulger GR, Natland JH, Presnall DC, Anderson DL (eds) Geological society of America special paper 388. Geological Society of America, pp 477-501
Snider-Pellegrini A (1858) La Création et ses mystères dévoilés ("Creation and its Mysteries Unveiled"). Franck et Dentu, Paris

Vine FJ, Matthews DH (1963) Magnetic anomalies over oceanic ridges. Nature 199:947-949

Wegener AL (1912) Die Entstehung der Kontinente. Geol Rundschau 3:276-292

Wegener A (1929) Die Entstehung der Kontinente und Ozeane (trans: Biram J), 4th edn. Friedr. Vieweg \& Sohn, Braunschweig

Wetherill GW (1980) Formation of the terrestrial planets. Ann Rev Astron Astrophys 18:77-113

Zhao D (2001) Seismic structure and origin of hotspots and mantle plumes. Earth Planet Sci Lett 192:251-265 